\title{
Time trends in the epidemiology and outcome of perianal fistulizing Crohn's disease in a population- based cohort
}

\author{
Citation for published version (APA):
}

Gottgens, K. W. A., Jeuring, S. F. G., Sturkenboom, R., Romberg-Camps, M. J. L., Oostenbrug, L. E., Jonkers, D. M. A. E., Stassen, L. P. S., Masclee, A. A. M., Pierik, M. J., \& Breukink, S. O. (2017). Time trends in the epidemiology and outcome of perianal fistulizing Crohn's disease in a population-based cohort. European Journal of Gastroenterology \& Hepatology, 29(5), 595-601.

https://doi.org/10.1097/MEG.0000000000000840

Document status and date:

Published: 01/05/2017

DOI:

10.1097/MEG.0000000000000840

Document Version:

Publisher's PDF, also known as Version of record

\section{Document license:}

Taverne

Please check the document version of this publication:

- A submitted manuscript is the version of the article upon submission and before peer-review. There can be important differences between the submitted version and the official published version of record.

People interested in the research are advised to contact the author for the final version of the publication, or visit the DOI to the publisher's website.

- The final author version and the galley proof are versions of the publication after peer review.

- The final published version features the final layout of the paper including the volume, issue and page numbers.

Link to publication

\footnotetext{
General rights rights.

- You may freely distribute the URL identifying the publication in the public portal. please follow below link for the End User Agreement:

www.umlib.nl/taverne-license

Take down policy

If you believe that this document breaches copyright please contact us at:

repository@maastrichtuniversity.nl

providing details and we will investigate your claim.
}

Copyright and moral rights for the publications made accessible in the public portal are retained by the authors and/or other copyright owners and it is a condition of accessing publications that users recognise and abide by the legal requirements associated with these

- Users may download and print one copy of any publication from the public portal for the purpose of private study or research.

- You may not further distribute the material or use it for any profit-making activity or commercial gain

If the publication is distributed under the terms of Article 25fa of the Dutch Copyright Act, indicated by the "Taverne" license above, 


\title{
Time trends in the epidemiology and outcome of perianal fistulizing Crohn's disease in a population-based cohort
}

Kevin W.A. Göttgens ${ }^{a, \star}$, Steven F.G. Jeuring ${ }^{b, c, \star}$, Rosel Sturkenboom ${ }^{a}$, Mariëlle J.L. Romberg-Camps ${ }^{d}$, Liekele E. Oostenbrug ${ }^{e}$, Daisy M.A.E. Jonkers ${ }^{\mathrm{b}, \mathrm{c}}$, Laurents P.S. Stassen ${ }^{\mathrm{a}}$, Ad A.M. Masclee ${ }^{\mathrm{b}, \mathrm{c}}$, Marieke J. Pierik ${ }^{\mathrm{b}, \mathrm{c}}$ and Stéphanie O. Breukink ${ }^{a}$

\begin{abstract}
Objective Perianal disease is a debilitating condition that frequently occurs in Crohn's disease (CD) patients. It is currently unknown whether its incidence has changed in the era of frequent immunomodulator use and biological availability. We studied the incidence and outcome of perianal and rectovaginal fistulas over the past two decades in our population-based Inflammatory
\end{abstract} Bowel Disease South-Limburg cohort.

Patients and methods All 1162 CD patients registered in the Inflammatory Bowel Disease South-Limburg registry were included. The cumulative probabilities of developing a perianal and rectovaginal fistula were compared between three eras distinguished by the year of CD diagnosis: 1991-1998, 1999-2005 and 2006-2011. Second, clinical risk factors and the risk of fistula recurrence were determined.

Results The cumulative 5-year perianal fistula rate was $14.1 \%$ in the $1991-1998$ era, $10.4 \%$ in the $1999-2005$ era and $10.3 \%$ in the 2006-2011 era, $P=0.70$. Colonic disease was associated with an increased risk of developing perianal disease, whereas older age was associated with a decreased risk (both $P<0.01$ ). Over time, more patients were exposed to immunomodulators or biologicals before fistula diagnosis (18.5 vs. 32.1 vs. $52.1 \%$, respectively, $P=0.02$ ) and started biological therapy thereafter (18.6 vs. 34.1 vs. $54.0 \%$, respectively, $P<0.01$ ). The cumulative 5 -year perianal fistula recurrence rate was not significantly different between eras ( 19.5 vs. 25.5 vs. $33.1 \%, P=0.28$ ). In contrast, the cumulative 5 -year rectovaginal rate attenuated from $5.7 \%$ (the $1991-2005$ era) to $1.7 \%$ (the 2006-2011 era), $P=0.01$.

Conclusion Over the past two decades, the risk of developing a perianal fistula was stable, as well as its recurrence rate, underlining the lasting need for improving treatment strategies for this invalidating condition. Eur $\mathrm{J}$ Gastroenterol Hepatol 29:595-601

Copyright () 2017 Wolters Kluwer Health, Inc. All rights reserved.

\section{Introduction}

Crohn's disease $(\mathrm{CD})$ is a chronic inflammatory disease that can affect the entire gastrointestinal tract, including the anus. Perianal CD is present in $10-37 \%$ of patients at the time of diagnosis and may even be the presenting symptom [1-3]. Perianal CD is an umbrella term for perianal abscesses, skin tags, fissures, strictures and fistulas

\footnotetext{
European Journal of Gastroenterology \& Hepatology 2017, 29:595-601

Keywords: Crohn's disease, epidemiology, perianal fistula, populationbased cohort

Departments of aGeneral Surgery, 'bnternal Medicine, Division of

Gastroenterology-Hepatology, "School of Nutrition and Translational Research in Metabolism (NUTRIM), Maastricht University Medical Centre, Maastricht,

dDepartment of Internal Medicine and Gastroenterology-Hepatology, Zuyderland

Medical Centre, Sittard-Geleen and eDepartment of Internal Medicine and

Gastroenterology-Hepatology, Zuyderland Medical Centre, Heerlen, The

Netherlands

Correspondence to Steven F.G. Jeuring, MD, Department of Internal Medicine, Division of Gastroenterology-Hepatology, Maastricht University Medical Centre,

Post box 5800, 6202 AZ Maastricht, The Netherlands

Tel: +31 433884 202; fax: +31 433875 093;

e-mail: steven.jeuring@maastrichtuniversity.nl

*Kevin W.A. Göttgens and Steven F.G. Jeuring contributed equally to the writing of this article.

Received 21 September 2016 Accepted 12 December 2016
}

[4]. Perianal fistulizing CD comprise perianal fistulas (PF) and rectovaginal fistulas (RVF) and is probably the most debilitating form of perianal CD. The natural history is characterized by frequent episodes of ductal discharge, abscess formation and perianal pain, often impairing patients' daily functioning and quality of life [5].

Several cohort studies have investigated the incidence of perianal CD. Population-based studies are preferred when studying the epidemiology of fistulizing CD because selection bias is likely to occur in referral centre studies as perianal fistulas are often treatment refractory and, as a result, patients are often referred to specialized centres. In population-based studies, the incidence of PFs in CD patients is estimated to be between 13 and $28 \%$ [1,6-9]. Most incidence and outcome data derive from studies that recruited patients decades ago. An update of these data has recently been considered an 'unmet need' in the field of PFs [10] and is needed to assess the risk of developing fistulizing disease in an era in which immunomodulators and biologicals are more frequently used in the medical management of CD.

Therefore, the aim of this study was to assess the incidence of PFs in our population-based inflammatory bowel disease (IBD) cohort and to study the evolution thereof in patients diagnosed between 1991 and 2011, followed until 
2014. Second, we aimed to study the incidence of RVFs specifically, to identify clinical risk factors for PF, and to assess changes in PF outcome over the past two decades.

\section{Patients and methods}

\section{Cohort description and study population}

The IBD South-Limburg (IBDSL) cohort is a populationbased IBD cohort in the well-defined South-Limburg area of the Netherlands, with a completeness of over $93 \%$. The cohort has been described in detail previously [11,12]. In brief, incident adult IBD cases in the area are being registered as from 1991 and data on demographics, disease phenotype, IBD medication, IBD-related complications (including fistulas), hospitalizations and surgeries are being collected. All data are retrieved directly from the medical files using standardized registration forms. For this study, all 1162 CD patients in the IBDSL registry were included. These patients were diagnosed between January 1991 and July 2011 at the age of 18 years or older. Patients were followed from the date of diagnosis to the end of data collection (2014), migration out of the area or death. IBDSL has been approved by the Ethics Committee of the Maastricht University Medical Centre (NL31636.068.10) and is registered in https://clinicaltrials.gov (NCT02130349).

\section{Study endpoints}

The primary endpoint of the study was the evolution of the incidence of PF in CD patients over the past two decades. To assess the time trend, the full cohort (1991-2011) was equally divided into three separate eras, also considering the registration of antitumour necrosis factor-alpha (antiTNF $\alpha$ ) agents in the Netherlands in 1999. The 1991-1998 era included patients with a CD diagnosis between 1991 and 1998, the 1999-2005 era included patients diagnosed between 1999 and 2005 and the 2006-2011 era included patients diagnosed between 2006 and 2011. The secondary endpoints were time trends in the incidence of RVFs, clinical risk factors for PFs and RVFs, and the evolution of the outcome of PFs in terms of the need for surgery and fistula recurrence. Furthermore, type of IBD therapy before fistula diagnosis was noted, even as changes in CD therapy after fistula diagnosis. Treatment status was determined considering all fistulas that occurred during the course of $\mathrm{CD}$ and considering fistulas that developed within 5 years after CD diagnosis to adjust for differences in the maximum follow-up of the three eras.

\section{Definitions}

PFs and RVFs were identified by a thorough review of the medical records of all CD patients. Fistulas diagnosed by either radiologic imaging or a physical examination were included for study. If imaging data (or endoanal ultrasound) were available, the PF was subsequently classified by two authors (K.G./S.B.), including an experienced gastrointestinal surgeon, or the classification was extracted from the radiologic report. In case classification was not possible, because radiologic imaging was not performed or unavailable, the classification was coded 'unknown'. PFs were classified according to (i) its relation to the sphincter muscle (low or high fistula) [13], (ii) the Park classification
[14] and (iii) the simple/complex classification [4]. A low fistula was defined as a fistula involving the lower onethird of the sphincter complex and a high fistula was defined as a fistula traversing the middle and/or the upper third part [13]. A fistula was classified as a simple fistula if a low superficial, intersphincteric or transsphincteric fistula was observed without complicating factors such as multiple tracts, abscesses or strictures. A complex fistula is a simple fistula with the aforementioned complications or a high fistula [4]. RVFs were described separately in this study and classified as either a low or a high fistula. Low fistulas involve the lower half of the rectovaginal septum and high fistulas involved the upper half. In this study, a fistula recurrence was defined as either a visible new fistula at the same location or the return of symptoms after a symptom-free period.

Disease phenotype was classified according to the Montreal consensus [15,16]. In contrast to the older Vienna classification [17], PFs are not included in the definition of a penetrating disease behaviour (B3), but classified separately.

\section{Statistical analyses}

Continuous data are presented as means with SDs or medians with interquartile ranges (IQR), depending on the normality of the underlying distribution, and subsequently compared between groups using an independent Student's $t$-test or the Mann-Whitney U-test, respectively. Discrete data are presented as absolute numbers with percentages and subsequently compared between groups using $\chi^{2}$-tests. Kaplan-Meier survival analyses were used to estimate the cumulative probabilities of developing a PF or an RVF over time to adjust for follow-up differences between patients. PFs and RVFs present before CD diagnosis were described separately, but considered to have developed at the time of diagnosis in the cumulative probability analyses to include these fistulas in the cumulative incidence rates. Cox regression models were established to assess associations between fistula incidence and era of diagnosis, adjusting for age at diagnosis, sex, disease location and disease behaviour. Because of the low number of RVFs in the cohort, only univariable models could be used for RVF analyses. Cox regression model data were expressed as hazard ratios (HR) with accompanying 95\% confidence intervals (95\% CI). A $P$-value lower than 0.05 was considered statistically significant. All statistical analyses were carried out using SPSS, version 21 (IBM Corp., Armonk, New York, USA).

\section{Results}

In the IBDSL database, $1162 \mathrm{CD}$ patients were identified. The patient group included $728(62.7 \%)$ female patients. The mean age at CD diagnosis was 37.7 (SD: 15.9) years and the mean follow-up duration was 8.7 (SD: 5.7) years. Of the 1162 patients, 316 patients were diagnosed in the 1991-1998 era, 387 patients in the 1999-2005 era and 459 patients in the 2006-2011 era. Over time, the cumulative 1 -year and 5 -year exposure to immunomodulators increased from 9.1 and $30.6 \%$ (the 1991-1998 era) to 31.0 and $56.7 \%$ (the $1999-2005$ era) to 49.5 and $70.8 \%$ (the 2006-2011 era), $P<0.01$. Similarly, the cumulative 1 -year and 5-year exposure to anti-TNF $\alpha$ agents increased: 
Table 1. Patient characteristics of Crohn's disease patients of the IBDSL cohort with and without perianal or rectovaginal fistulas

$n(\%)$

CD patients without PF/RVF $(N=995) \quad$ CD patients with only a PF $(N=150) \quad$ CD patients with a RVF $(N=17)$

\begin{tabular}{|c|c|c|c|c|}
\hline Age at diagnosis mean (SD) & $38.5(16.3)$ & $32.3(12.5)$ & $37.3(15.1)$ & $\begin{array}{l}P_{1}<0.01 \\
P_{2}=0.78\end{array}$ \\
\hline Sex: female & $620(62.3)$ & $91(60.7)$ & $17(100)$ & $P_{1}=0.72$ \\
\hline Current smoker at diagnosis ${ }^{a}$ & $420(49.8)$ & 70 (49.6) & $7(46.7)$ & $P_{1}=0.99$ \\
\hline Follow-up (years) [mean (SD)] & $8.3(5.6)$ & $11.1(5.8)$ & $13.6(5.8)$ & $\begin{array}{l}P_{1}<0.01 \\
P_{2}<0.01\end{array}$ \\
\hline Disease location at diagnosis ${ }^{b}$ & & & & $\begin{array}{l}P_{1}=0.03 \\
P_{2}=0.23\end{array}$ \\
\hline L1 - ileal location & $448(45.0)$ & $48(32.0)$ & $4(23.5)$ & \\
\hline L2 - colon location & $305(30.7)$ & $58(38.7)$ & $8(47.1)$ & \\
\hline L3 - ileocolon location & $222(22.3)$ & $40(26.7)$ & $5(29.4)$ & \\
\hline L4 - only upper Gl location & $20(2.0)$ & $4(2.7)$ & - & \\
\hline Disease behaviour at diagnosis ${ }^{\mathrm{b}}$ & & & & $\begin{array}{l}P_{1}=0.52 \\
P_{2}=0.20\end{array}$ \\
\hline B1 - inflammatory & $773(77.7)$ & $116(77.3)$ & $11(64.7)$ & \\
\hline B2 - stricturing & $148(14.9)$ & $26(17.3)$ & $3(17.6)$ & \\
\hline B3 - penetrating & $74(7.4)$ & $8(5.3)$ & $3(17.6)$ & \\
\hline
\end{tabular}

$\mathrm{CD}$, Crohn's disease; PF, perianal fistula; RVF, rectovaginal fistula.

$P_{1}-P$-value of the comparison CD patients without PF/RVF versus CD patients with a PF.

$P_{2}-P$-value of the comparison CD patients without PF/RVF versus CD patients with a RVF.

a Smoking status at diagnosis was not available in 169 cases.

${ }^{\mathrm{b}}$ Disease location and behaviour were classified according to the Montreal consensus.

0 and $3.1 \%$ in the $1991-1998$ era, 7.1 and $19.9 \%$ in the 1999-2005 era and 21.2 and $41.2 \%$ in the 2006-2011 era, $P<0.01$. We identified $284(24.4 \%)$ patients with fistulizing disease (including perianal, rectovaginal, enterocutaneous and enteroenteral fistulas). The number of patients with a PF and/or an RVF was 163 (14.0\%). Of these patients, $161(13.9 \%)$ ever had a PF, $17(2.3 \%)$ women ever had an RVF and 15 (2.1\%) women ever suffered from both a PF and an RVF. Patient characteristics of CD patients with and without fistulas are shown in Table 1.

\section{Perianal fistula incidence}

In total, $161(13.9 \%)$ CD patients ever had a PF. The classifications of these fistulas are shown in Table 2. Forty-

Table 2. Classifications of perianal and rectovaginal fistulas

\begin{tabular}{|c|c|c|c|c|}
\hline & \multicolumn{4}{|c|}{$n(\%)$} \\
\hline & $\begin{array}{l}\text { All primary } \\
\text { perianal } \\
\text { fistulas } \\
(N=161)\end{array}$ & $\begin{array}{c}\text { Operated } \\
\text { primary } \\
\text { perianal } \\
\text { fistulas } \\
(N=95)\end{array}$ & $\begin{array}{c}\text { Perianal } \\
\text { fistula } \\
\text { recurrences } \\
(N=59)\end{array}$ & $\begin{array}{c}\text { Rectovaginal } \\
\text { fistulas } \\
(N=17)\end{array}$ \\
\hline \multicolumn{5}{|c|}{ Low/high classification } \\
\hline Low fistula & 54 (33.5) & $34(35.8)$ & $11(18.6)$ & $6(35.3)$ \\
\hline High fistula & $36(22.4)$ & 32 (33.7) & $14(23.7)$ & $2(11.8)$ \\
\hline Unknown & $71(44.1)$ & $29(30.5)$ & $34(57.6)$ & $9(52.9)$ \\
\hline \multicolumn{5}{|l|}{ Park's classification } \\
\hline Intersphincteric & $36(22.4)$ & $22(23.2)$ & $14(23.7)$ & - \\
\hline Transsphincteric & $30(18.6)$ & $20(21.1)$ & $4(6.8)$ & - \\
\hline Extrasphincteric & $12(7.5)$ & $11(11.6)$ & $3(5.1)$ & - \\
\hline Suprasphincteric & 7 (4.3) & $6(6.3)$ & $3(5.1)$ & - \\
\hline Superficial & $15(9.3)$ & $7(7.4)$ & $2(3.4)$ & - \\
\hline Unknown & $61(37.9)$ & $29(30.5)$ & $33(55.9)$ & - \\
\hline \multicolumn{5}{|c|}{ Simple/complex classification } \\
\hline Simple & $39(24.2)$ & $20(21.1)$ & $12(20.3)$ & - \\
\hline Complex $^{a}$ & $39(24.2)$ & $29(30.5)$ & $9(15.3)$ & - \\
\hline Unknown & $83(51.6)$ & $46(48.4)$ & $38(64.4)$ & - \\
\hline
\end{tabular}

${ }^{\text {aRectovaginal fistulas were not considered complex perianal fistulas, but described }}$ separately. nine $(30.4 \%)$ patients developed the fistula before CD diagnosis at a median time of 0.8 (IQR: 0.2-2.7) years before diagnosis. The majority $(n=112,69.6 \%)$ developed a PF during the course of CD at a median time of 2.1 (IQR: 0.4-6.3) years after diagnosis. The overall cumulative probability of developing a PF during the course of the disease was $8.3 \%$ after 1 year, $11.6 \%$ after 5 years and $15.8 \%$ after 10 years. The cumulative 5 -year probability of developing a PF was not different between the three eras (14.1\% in the $1991-1998 \mathrm{era}, 10.4 \%$ in the $1999-2005$ era and $10.3 \%$ in the $2006-2011$ era, $P=0.70$; Fig. 1a). Results were concordant in the multivariable model, adjusted for age, sex, disease location and disease behaviour $(P=0.72)$. A colonic or an ileocolonic disease location at diagnosis was associated with an increased risk of developing a PF (adjusted HR: 1.90; 95\% CI: 1.29-2.81 and adjusted HR: 1.60; 95\% CI: 1.06-2.41, respectively). In addition, the cumulative 5-year PF risk was found to be the lowest in patients who were older in age at CD diagnosis: $18-40$ years, $13.6 \%, 40-60$ years, $8.5 \%$ and older than 60 years, $6.2 \%(P<0.01$; Table 3$)$. Medication status at $\mathrm{PF}$ diagnosis is shown in Fig. 2, stratified by era. Considering PFs that were diagnosed within 5 years after diagnosis $(n=78)$, an increasing number of patients had been exposed to immunomodulator and anti-TNF $\alpha$ agents before the diagnosis of PF: $18.5 \%$ (the 1991-1998 era) versus $32.1 \%$ (the $1999-2005$ era) versus $52.1 \%$ (the 2006-2011 era), $P=0.02$. In particular, the number of patients with previous exposure to anti-TNF $\alpha$ agents increased: $0 \%$ (the 1991-1998 era) versus $0 \%$ (the 1999-2005 era) versus $26.0 \%$ (the 2006-2011 era) $(P<0.01)$.

\section{Perianal fistula outcome}

Of the 161 primary PFs diagnosed, 133 (82.6\%) were treated with antibiotics. Ninety-nine $(61.5 \%)$ patients underwent surgery for a PF and the surgery rate was similar in the three eras $(55.9,63.6$ and $58.7 \%, P=0.71$, 
(a)

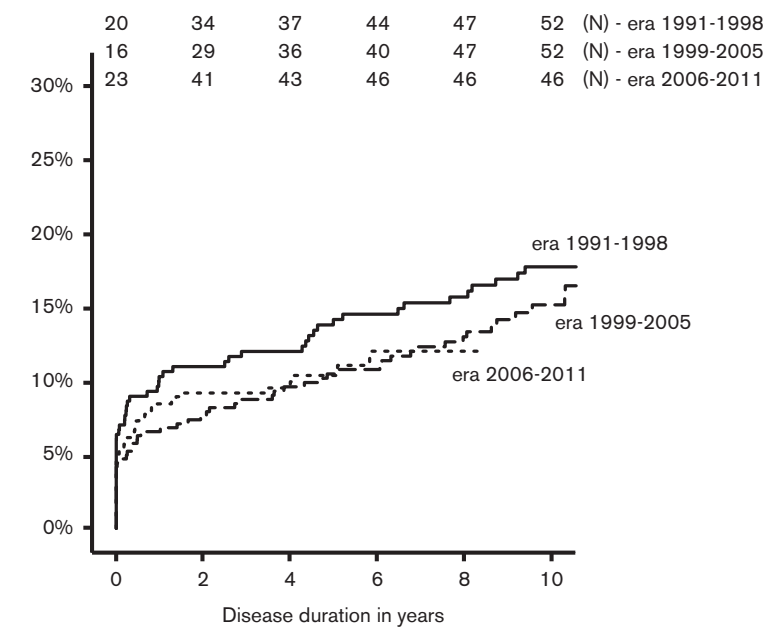

(b)

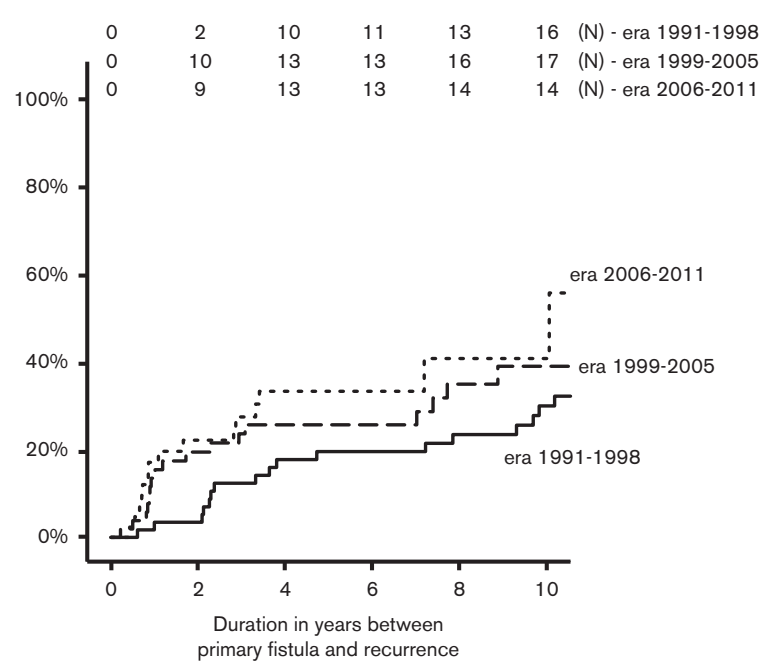

\begin{tabular}{|c|c|c|c|c|c|c|c|c|c|c|c|c|c|c|}
\hline No at risk & 316 & 262 & 248 & 229 & 211 & 193 era $1991-1998$ & No at risk & 59 & 55 & 45 & 43 & 39 & 32 & era $1991-1998$ \\
\hline No at risk & 387 & 340 & 316 & 297 & 251 & 144 era $1999-2005$ & No at risk & 55 & 40 & 33 & 27 & 18 & 13 & era $1999-2005$ \\
\hline No at risk & 459 & 356 & 216 & 77 & 4 & 0 era $2006-2011$ & No at risk & 46 & 31 & 20 & 14 & 6 & 4 & era $2006-2011$ \\
\hline
\end{tabular}

Fig. 1. Kaplan-Meier survival curves showing the cumulative probability of developing a primary perianal fistula (a) and a perianal fistula recurrence (b).

Table 3. Cox regression models for the risk of developing perianal fistulas and perianal fistula recurrences

\begin{tabular}{|c|c|c|c|c|}
\hline & \multicolumn{4}{|c|}{ HR $(95 \% \mathrm{Cl})$} \\
\hline & \multicolumn{2}{|c|}{ Risk of developing a perianal fistula } & \multicolumn{2}{|c|}{ Risk of developing a perianal fistula recurrence } \\
\hline & Unadjusted hazard ratio & Adjusted hazard ratio & Unadjusted hazard ratio & Adjusted hazard ratio \\
\hline \multicolumn{5}{|l|}{ Age at diagnosis (years) } \\
\hline $18-40$ & Reference & Reference & Reference & Reference \\
\hline $40-60$ & $0.51(0.33-0.79)$ & $0.52(0.33-0.81)$ & $1.12(0.55-2.29)$ & - \\
\hline$>60$ & $0.42(0.22-0.84)$ & $0.45(0.23-0.90)$ & $0.50(0.07-3.65)$ & - \\
\hline \multicolumn{5}{|l|}{ Sex } \\
\hline Male & Reference & Reference & Reference & Reference \\
\hline Female & $1.01(0.74-1.40)$ & $0.91(0.66-1.26)$ & $1.18(0.69-2.03)$ & $1.28(0.73-2.26)$ \\
\hline \multicolumn{5}{|l|}{ Era } \\
\hline $1991-1998$ & Reference & Reference & Reference & Reference \\
\hline $1999-2005$ & $0.88(0.61-1.28)$ & $0.87(0.60-1.27)$ & $1.16(0.62-2.17)$ & $1.23(0.64-2.36)$ \\
\hline $2006-2011$ & $0.85(0.57-1.28)$ & $0.86(0.57-1.31)$ & $1.70(0.86-3.33)$ & $1.85(0.92-3.73)$ \\
\hline \multicolumn{5}{|l|}{ Disease location at diagnosis } \\
\hline L1 - ileal location & Reference & Reference & Reference & Reference \\
\hline L2 - colon location & $1.89(1.30-2.74)$ & $1.90(1.29-2.81)$ & $1.50(0.82-2.78)$ & $1.53(0.82-2.85)$ \\
\hline L3 - ileocolon location & $1.76(1.18-2.64)$ & $1.60(1.06-2.41)$ & $0.87(0.41-1.85)$ & $0.92(0.43-1.98)$ \\
\hline L4 - only upper Gl location & $1.86(0.67-5.14)$ & $2.51(0.78-8.14)$ & $1.07(0.14-8.08)$ & $1.10(0.14-8.60)$ \\
\hline \multicolumn{5}{|l|}{ Disease behaviour at diagnosis } \\
\hline B1 - inflammatory disease & Reference & Reference & Reference & Reference \\
\hline B2 - stricturing disease & $1.06(0.70-1.61)$ & $1.20(0.78-1.84)$ & $0.88(0.43-1.80)$ & - \\
\hline B3 - penetrating disease & $0.78(0.41-1.48)$ & $0.89(0.46-1.73)$ & $0.72(0.22-2.36)$ & - \\
\hline \multicolumn{5}{|l|}{ Upper Gl location at diagnosis } \\
\hline No & Reference & Reference & Reference & Reference \\
\hline Yes & $0.87(0.51-1.49)$ & $0.85(0.46-1.58)$ & $1.08(0.43-2.69)$ & - \\
\hline
\end{tabular}

$\mathrm{Cl}$, confidence interval; $\mathrm{HR}$, hazard ratio.

respectively). Thirty-four $(63.0 \%)$ patients with a low $\mathrm{PF}$ were operated (all fistulotomy) and $32(88.9 \%)$ patients with a high PF required surgery.

Adjustments to $\mathrm{CD}$ maintenance therapy upon PF diagnosis were made in 46 of the 112 patients who developed a PF during the course of the disease $(41.1 \%)$, adjustments being more common in more recently diagnosed patients: $27.9 \%$ in the $1991-1998$ era versus $47.7 \%$ in the $1999-2005$ era versus $52.0 \%$ in the $2006-2011$ era, $P=0.04$. After PF diagnosis, an increasing number of CD patients were on anti-TNF $\alpha$ therapy (the 1991-1998 era:
$18.6 \%$, the $1999-2005$ era: $34.1 \%$, the $2006-2011$ era: $54.0 \%, P<0.01)$, most $(69.5 \%)$ in combination with immunomodulator therapy (Fig. 2).

In total, $58(36.0 \%)$ patients developed a PF recurrence. The cumulative probability of a PF recurrence was $10.7 \%$ 1 year, $25.7 \% 5$ years and $36.7 \% 10$ years after the diagnosis of the primary PF. The median duration between the primary PF and recurrent PF was 2.9 (IQR: 0.9-9.0) years. The cumulative 5 -year recurrence rate was not found to be significantly different between eras: $19.5 \%$ 
(a) Medication use before perianal fistula diagnosis

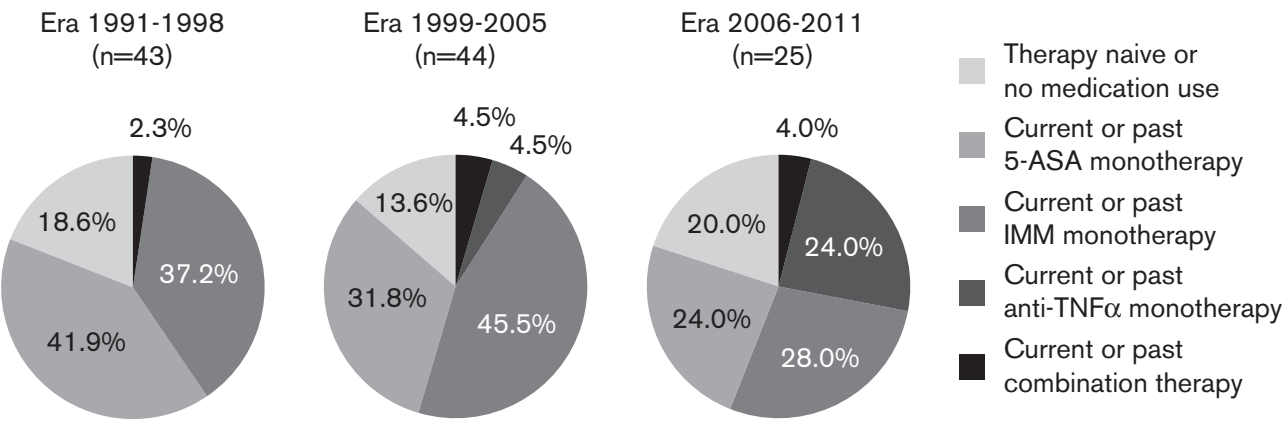

(b) Medication use after perianal fistula diagnosis

$\begin{array}{cc}\text { Era } \\ (n=43) & \text { Era } 1991-1998 \\ (n=44)\end{array}$

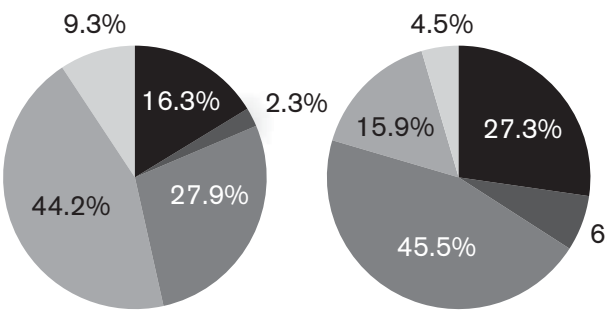

Era 2006-2011 $(n=25)$

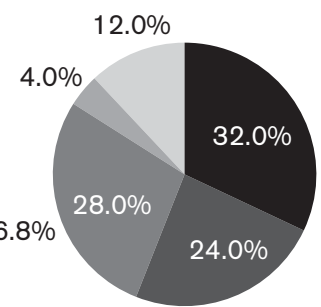

Therapy naive or no medication use

Current or past

5-ASA monotherapy

Current or past

IMM monotherapy

Current or past

anti-TNF $\alpha$ monotherapy

Current or past

combination therapy

Fig. 2. Medication use before (a) and after (b) the diagnosis of perianal fistulas that developed during the course of the disease. 5-ASA, 5-aminosalicylate; IMM, initial methotrexate monotherapy; TNF- $\alpha$, tumor necrosis factor- $\alpha$.

(the $1991-1998$ era) versus $25.5 \%$ (the $1999-2005$ era) versus $33.1 \%$ (the $2006-2011$ era), $P=0.22$ (adjusted for sex and disease location) (Fig. $1 \mathrm{~b}$ and Table 3). The cumulative 5 -year recurrence rate was found to be higher in patients who required surgery for their primary PF than in patients who were treated medically (33.0 vs. $13.8 \%$, HR: 4.08; 95\% CI: 1.98-8.38).

\section{Rectovaginal fistula incidence}

In total, 17 of the $728(2.3 \%)$ female CD patients ever had an RVF. Two (11.8\%) patients already had an RVF before $\mathrm{CD}$ diagnosis, with a time to $\mathrm{CD}$ diagnosis of 0.2 and 6.7 years. The other $15 \mathrm{RVFs}$ developed during the course of disease at a median of 4.7 (IQR: 1.3-8.1) years after CD diagnosis. The overall cumulative probability of developing an RVF was $0.7 \%$ after 1 year, $1.7 \%$ after 5 years and $3.1 \%$ after 10 years. For these analyses, eras 1999-2005 and 2006-2011 were combined and subsequently compared with the 1991-1998 era because of the small number of events $(n=17)$. The cumulative 10 -year probability of developing an RVF was significantly lower in the $1999-2011$ era than in the $1991-1998$ era (1.7 vs. $5.7 \%$, HR: 0.28 ; 95\% CI: 0.10-0.78, respectively; see Fig. 3). Because of the limited number of events, only univariable analyses could be carried out to assess the risk factors for developing an RVF. No significant associations were found with age $(P=0.11)$, disease location $(P=0.47)$ or disease behaviour $(P=0.16)$.

Seven of the $10(70.0 \%)$ patients in the 1991-1998 era with an RVF who developed during the course of the disease had been exposed previously to immunomodulator

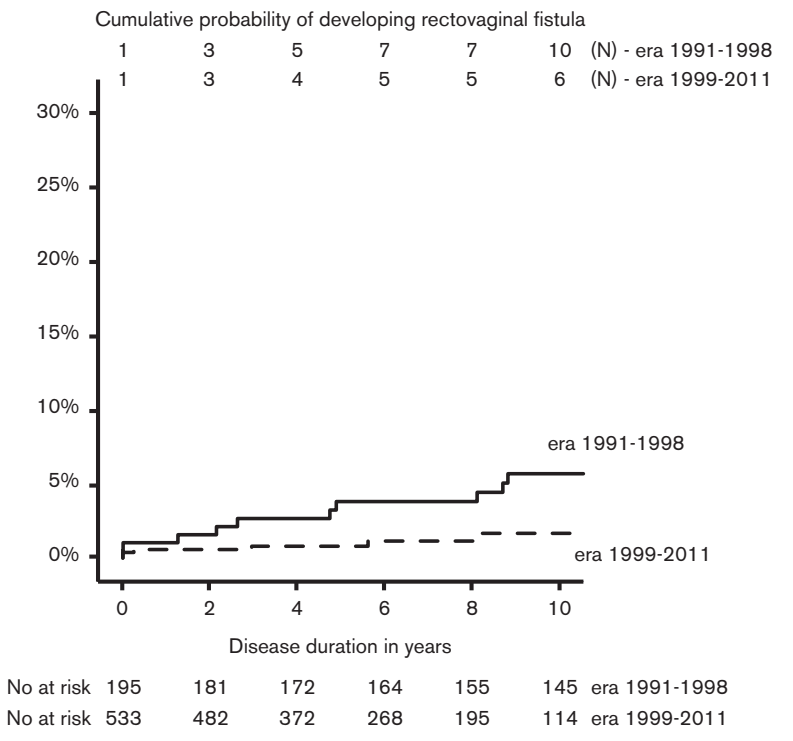

Fig. 3. Kaplan-Meier survival curve showing the cumulative probability of developing a rectovaginal fistula.

or anti-TNF $\alpha$ therapy compared with three of the five $(60.0 \%)$ patients in the $1999-2011$ era.

\section{Discussion}

In this population-based cohort study, we observed a stable cumulative 5 -year PF risk of $11.6 \%$ over the past two decades, whereas the cumulative 5-year RVF risk decreased from $5.7 \%$ in patients diagnosed between 1991 
and 1998 to $1.7 \%$ in patients diagnosed between 1999 and 2011. Over time, more patients are exposed to immunomodulator or anti-TNF $\alpha$ therapy; also before PF diagnosis, and an increasing number of patients received anti-TNF $\alpha$ therapy after fistula diagnosis. Patients with colon involvement had a higher risk of $\mathrm{PF}$ and older patients had a lower risk of developing a PF. More than half of the patients $(61.5 \%)$ required a surgical intervention and the surgery rate remained stable over time. The cumulative 5-year risk of recurrence of PF was $25.7 \%$, which was also stable over the past 20 years.

The present study is the first to study the evolution of the PF incidence in a large population-based cohort of CD patients in an era in which the medical management of CD and CD-related PFs changed significantly. Overall, a PF incidence of $13.9 \%$ was observed, which is very similar to the rates observed in other population-based cohorts, such as Stockholm County $(13.7 \%)$ [6] and Manitoba (9.9-14.0\%) [7]. Moreover, the cumulative 10-year PF risk of $15.8 \%$ observed in our cohort is in line with the cumulative 10-year risk observed in Minnesota (21\%) [1] and Canterbury (16.9\%) [8]. Over the past two decades, the cumulative PF risk was stable in our CD population. In parallel, marked changes have occurred in the medical management of $\mathrm{CD}$ and the medical management of CDrelated PFs, reflected by an increasing number of CD patients exposed to immunomodulators and anti-TNF $\alpha$ agents in general and before PF diagnosis. In a clinical trial that compared the effects of early azathioprine administration versus conventional management of $\mathrm{CD}$, the authors found a lower risk of having active perianal lesions (14 vs. $27 \%, P=0.049$ ) and perianal surgery ( 3 vs. $13 \%$, $P=0.04)$ in the treatment arm that commenced immunomodulator therapy within 6 months after diagnosis compared with conventional management, respectively [18]. Hence, it could be expected that the incidence of PF is lower in more recent eras, given that the number of patients who are exposed early to immunomodulators is increasing. However, the results of the present study do not confirm these findings. A possible explanation for this discrepancy may reside in the fact that, even in the most recent era, only $40.7 \%$ of the CD patients in the IBDSL cohort were exposed to immunomodulators within 6 months after diagnosis (data not shown). Consequently, a potential beneficial effect of immunomodulator therapy on fistula development may therefore be not present at the population level. Ultimately, early azathioprine use may prevent the development of PF and PF surgery, but our findings support the conduction of future studies that should look at the number needed to treat early with immunomodulator therapy to prevent one PF. These findings should then be considered in the clinical discussion on balancing the risks and benefits of early and longstanding immunomodulator therapy.

The PF recurrence rate was $36.7 \%$ within 10 years after the primary PF. Cohort studies evaluating PF recurrences are scarce and definitions vary, not allowing a direct comparion of recurrence rates. Schwartz et al. [1] observed a recurrence rate of $33 \%$ in CD patients diagnosed between 1970 and 1993 at a median time of 2.8 years after the primary PF. In a referral hospital setting, $6 \%$ of simple $\mathrm{PF}$ persisted and $32 \%$ relapsed after a median of 30 months, whereas $30 \%$ of the complex PF persisted and
$23 \%$ relapsed after a median of 11 months [19]. In line with previously discussed changes in medical management, we observed that, over time, an increasing number of CD patients were on immunomodulator or anti-TNF $\alpha$ therapy after the diagnosis of the primary PF, in line with current European and Dutch guidelines [20,21]. It is noteworthy that more than half $(54.0 \%)$ of the most recently diagnosed CD patients were on anti-TNF $\alpha$ therapy after PF diagnosis, either as monotherapy or as combination therapy with immunomodulators. We found no significant differences in the PF recurrence rate between the three eras, indicating that changes in the medical management of PF seemed not to have resulted in fewer PF recurrences in general. However, we must acknowledge that the implementation of MRI and endoanal ultrasound in the followup of $\mathrm{CD}$ and PF, in particular, may have had impact on the reported recurrence rate as subclinical PFs may have been more often detected in more recent eras.

Next to changes in medical therapy, surgical techniques for high PFs have also changed over the past two decades, whereas treatment of low PFs has remained unchanged (fistulotomy). For a long time, the seton and mucosal advancement flap were the most used techniques to treat high PFs. In addition to these classic surgical treatment options, several other techniques have been used over the years in our area, such as fibrin glue [22,23], fistula plugs [23], ligation of the intersphincteric fistula tract [24] and, more recently, endoscopic techniques [25] and the local injection of stem cells [26] or platelet-rich plasma [27] and variations on all these treatment options [28]. Regrettably, we could not obtain detailed information on the specific surgical technique used in operated patients from our cohort. However, the number of patients treated with these new techniques is limited, and as such, the outcome of high PFs from the present study can mainly be interpreted as the outcome after seton and mucosal advancement flap interventions. Ultimately, the stable recurrence rate and the stable high surgery rate observed in this study underline the importance of developing new surgical procedures and the need for a direct comparison of current surgical treatment options.

The prevalence of RVFs in the IBDSL cohort was rather low (2.3\% in female CD patients). Nevertheless, we found that the incidence of RVFs was significantly lower in the second decade of our cohort. The reason for this decrease is unclear. Further elaboration on this finding is warranted, particularly because a different time trend was found for PFs. Unfortunately, the low number of RVFs in the present study impeded further elaboration on this finding. As this is the first study that looked into the time trend of RVF incidence, future studies should confirm our observation.

Risk factors for the development of PFs have been reported in several cohort studies $[1,6,7,9]$. In line with these studies, we observed that an older age at CD diagnosis was associated with a lower risk of developing PFs, whereas colonic disease involvement was found to be associated with an increased risk of developing PFs. We did not find sex to be related to the development of a PF, which may be related to the fact that we analysed RVFs separately.

The strengths of the present study are its populationbased nature, the long follow-up of patients and the long 
period of patient inclusion. This allowed us to study time trends in the PF and RVF incidences in an unselected, representative population of CD patients. Some limitations have to be addressed. First, the retrospective identification of the fistulas on the basis of medical files might have resulted in an under-representation of the true incidence of fistula, especially in the first era, in which imaging was not as commonly used in the diagnosis and follow-up of PFs and RVFs as it is nowadays. As a result, a theoretical decrease in the incidence of fistula over time might have been missed because of a parallel increase in the use of (new) diagnostic procedures. Second, the lack of detailed data on the specific surgical procedure did not allow a direct comparison of surgical techniques, which would have been of interest, considering the lack of comparative trials on this subject.

In conclusion, PFs are still common nowadays and the recurrence rate remains high, despite changes in treatment options and strategies for CD and CD-related fistulas over the past two decades. RVFs occur less frequently in $\mathrm{CD}$ patients and its incidence has decreased over time. The findings of the present study underline the lasting importance of improving medical and surgical treatment strategies for these invalidating conditions.

\section{Acknowledgements}

Part of this work was supported by funding from the European Union Seventh Framework Programme (FP7/2007-2013), under grant agreement no. 305564.

\section{Conflicts of interest}

M.P. has acted as consultant for MSD and Takeda and received payments for lectures from MSD, Dr. Falk Pharma, Abbvie and Ferring. A.M. has received research funding from DSM, Grunenthal, Abbvie and Danone. S.B. has received unrestricted research grants from Medtronic, not related to this project. For the remaining authors there are no conflicts of interest.

\section{References}

1 Schwartz DA, Loftus EV Jr, Tremaine WJ, Panaccione R, Harmsen WS, Zinsmeister AR, et al. The natural history of fistulizing Crohn's disease in Olmsted County, Minnesota. Gastroenterology 2002; 122:875-880.

2 Lakatos PL, Golovics PA, David G, Pandur T, Erdelyi Z, Horvath A, et al. Has there been a change in the natural history of Crohn's disease? Surgical rates and medical management in a population-based inception cohort from Western Hungary between 1977-2009. Am J Gastroenterol 2012; 107:579-588.

3 Lapidus A, Bernell O, Hellers G, Lofberg R. Clinical course of colorectal Crohn's disease: a 35-year follow-up study of 507 patients. Gastroenterology 1998; 114:1151-1160.

4 Sandborn WJ, Fazio WW, Feagan BG, Hanauer SB. American Gastroenterological Association Clinical Practice C. AGA technical review on perianal Crohn's disease. Gastroenterology 2003; 125: 1508-1530.

5 Andersson P, Olaison G, Bendtsen P, Myrelid P, Sjodahl R. Health related quality of life in Crohn's proctocolitis does not differ from a general population when in remission. Colorectal Dis 2003; 5:56-62.

6 Lapidus A. Crohn's disease in Stockholm County during 1990-2001: an epidemiological update. World J Gastroenterol 2006; 12:75-81.

7 Tang LY, Rawsthorne P, Bernstein CN. Are perineal and luminal fistulas associated in Crohn's disease? A population-based study. Clin Gastroenterol Hepatol 2006; 4:1130-1134.
8 Eglinton TW, Barclay ML, Gearry RB, Frizelle FA. The spectrum of perianal Crohn's disease in a population-based cohort. Dis Colon Rectum 2012; 55:773-777.

9 Hellers G, Bergstrand O, Ewerth S, Holmstrom B. Occurrence and outcome after primary treatment of anal fistulae in Crohn's disease. Gut 1980; 21:525-527.

10 Gecse KB, Sebastian S, Hertogh G, Yassin NA, Kotze PG, Reinisch W, et al. Results of the fifth scientific workshop of the ECCO [III]: clinical aspects of perianal fistulising Crohn's disease - the unmet needs. J Crohns Colitis 2016; 10:758-765.

11 van den Heuvel TR, Jonkers DM, Jeuring SF, Romberg-Camps MJ, Oostenbrug LE, Zeegers MP, et al. Cohort profile: the Inflammatory Bowel Disease South Limburg Cohort (IBDSL). Int J Epidemiol 2015. [Epub ahead of print].

12 Romberg-Camps MJ, Dagnelie PC, Kester AD, Hesselink-van de Kruijs MA, Cilissen M, Engels LG, et al. Influence of phenotype at diagnosis and of other potential prognostic factors on the course of inflammatory bowel disease. Am J Gastroenterol 2009; 104:371-383.

13 Gottgens KW, Smeets RR, Stassen LP, Beets G, Breukink SO. Systematic review and meta-analysis of surgical interventions for high cryptoglandular perianal fistula. Int J Colorectal Dis 2015; 30:583-593.

14 Parks AG, Gordon PH, Hardcastle JD. A classification of fistula-in-ano. Br J Surg 1976; 63:1-12.

15 Silverberg MS, Satsangi J, Ahmad T, Arnott ID, Bernstein CN, Brant SR, et al. Toward an integrated clinical, molecular and serological classification of inflammatory bowel disease: report of a Working Party of the 2005 Montreal World Congress of Gastroenterology. Can J Gastroenterol 2005; 19 (Suppl A):5A-36A.

16 Satsangi J, Silverberg MS, Vermeire S, Colombel JF. The Montreal classification of inflammatory bowel disease: controversies, consensus, and implications. Gut 2006; 55:749-753.

17 Gasche C, Scholmerich J, Brynskov J, D'Haens G, Hanauer SB, Irvine EJ, et al. A simple classification of Crohn's disease: report of the Working Party for the World Congresses of Gastroenterology, Vienna 1998. Inflamm Bowel Dis 2000; 6:8-15.

18 Cosnes J, Bourrier A, Laharie D, Nahon S, Bouhnik Y, Carbonnel F, et al. Early administration of azathioprine vs conventional management of Crohn's Disease: a randomized controlled trial. Gastroenterology 2013; 145:758-765.

19 Bell SJ, Williams AB, Wiesel P, Wilkinson K, Cohen RC, Kamm MA. The clinical course of fistulating Crohn's disease. Aliment Pharmacol Ther 2003; 17:1145-1151.

20 Van Assche G, Dignass A, Reinisch W, van der Woude CJ, Sturm A, De Vos $\mathrm{M}$, et al. The second European evidence-based consensus on the diagnosis and management of Crohn's disease: special situations. J Crohns Colitis 2010; 4:63-101.

21 van Bodegraven AA, van Everdingen JJ, Dijkstra G, de Jong DJ, Oldenburg B, Hommes DW, et al. Guideline 'Diagnosis and treatment of inflammatory bowel disease in adults'. I. Diagnosis and treatment [Article in Dutch]. Ned Tijdschr Geneeskd 2010; 154:A1899.

22 Abel ME, Chiu YS, Russell TR, Volpe PA. Autologous fibrin glue in the treatment of rectovaginal and complex fistulas. Dis Colon Rectum 1993; 36:447-449.

23 Johnson EK, Gaw JU, Armstrong DN. Efficacy of anal fistula plug vs. fibrin glue in closure of anorectal fistulas. Dis Colon Rectum 2006; 49:371-376.

24 Rojanasakul A, Pattanaarun J, Sahakitrungruang C, Tantiphlachiva K. Total anal sphincter saving technique for fistula-in-ano; the ligation of intersphincteric fistula tract. J Med Assoc Thai 2007; 90:581-586.

25 Meinero P, Mori L. Video-assisted anal fistula treatment (VAAFT): a novel sphincter-saving procedure for treating complex anal fistulas. Tech Coloproctol 2011; 15:417-422.

26 Garcia-Olmo D, Herreros D, Pascual I, Pascual JA, Del-Valle E, Zorrilla J, et al. Expanded adipose-derived stem cells for the treatment of complex perianal fistula: a phase II clinical trial. Dis Colon Rectum 2009; 52:79-86.

27 van der Hagen SJ, Baeten CG, Soeters PB, van Gemert WG. Autologous platelet-derived growth factors (platelet-rich plasma) as an adjunct to mucosal advancement flap in high cryptoglandular perianal fistulae: a pilot study. Colorectal Dis 2011; 13:215-218.

28 Han JG, Yi BQ, Wang ZJ, Zheng Y, Cui JJ, Yu XQ, et al. Ligation of the intersphincteric fistula tract plus a bioprosthetic anal fistula plug (LIFTPlug): a new technique for fistula-in-ano. Colorectal Dis 2013; 15:582-586. 